\title{
Translating Drama: An Interpretation, an Investigation
}

G. SATYA GIRISH

K. RAJYARAMA

\section{Abstract}

This paper addresses the problems of translating dramatic texts from the viewpoints of the purpose of translation and the strategies involved. Issues like untranslatability of certain social aspects and lexical gaps between English and Telugu are discussed in detail drawing examples from two different texts published in different periods of time.

Keywords: Translation Studies, Telugu Drama, Untranslatability, Modernism, Problems of Translation.

\section{Introduction}

It is quite impossible for any language, which has a script of its own, to distance itself from translation. However, translation has not always been a respected practice for it was seen as a mere reproduction or imitation of the original. In his recent book, translator and author Mark Polizzotti (2018: 13) draws dichotomous perspectives on translation which prevail till date. He opines that for some, translation is the poor cousin of literature, fool's gold or a last resort, a necessary evil if not an outright travesty. For others, it is the royal road to crosscultural understanding and literary enrichment. Translation skirts the boundaries between art and craft, originality and replication, altruism and commerce, even between genius and hack work. Confirming to the latter part of this statement, this paper places itself at the intersection of culture, literature and translation.

Of all the literary practices, drama is distinct by nature, for the characters in a drama speak for themselves. It is a story in 
discourse. The most common perspective about drama is that the text exists for the sole purpose of facilitating performance on stage. At the same time, it is intended for the actors as well, along with the audience. Anne Ubersfeld (1999: XXIV) noted that any work that reflects upon the theatrical text will without fail come up against the problematics of performance. In her book, she conceptualized drama (in terms of watching it on stage and reading it as a text) as the inseparability of text and performance. While semioticians argued about the interrelation between text and the performance, other scholars also proposed translating dramatic texts with respect to performance. In this context, Susan Bassnett (2002: 124) opined that there is very little material on the special problems of translating dramatic texts and the statement of individual theatre translators often imply that the methodology used in the translation process is the same as that used to approach prose texts. Though Bassnett raised the actual problems of translations, much of her arguments were centred on performance, speakability and the rhythm in the text. While translating drama, adaptability, sense of theatre, speakability and target language acceptability stand as necessary prerequisites. Apart from these, figurative language, like simile, metaphor and idiom; language specific usages such as epithets, expletives, taboo and slang words make a text more vulnerable to translation loss. One reason is that epithets are not used with reference to the corresponding dictionary meaning and the other reason is that they are highly culture specific. Against this background, this paper explores the problematics of translation with reference to the value systems, institutional and cultural practices, social stigmas and taboos of a speech community. The paper focuses on morals, ethical and social values associated with women in certain socially stigmatized professions portrayed in different plays and concerns with problematics of translation. 
In order to understand the interplay of various facets involved in the process of translation, women characters from two different plays - Kanyasulkam and Chavakudadu - have been examined in tandem. Though they both differ in the context, period, setting and length, they share a few common traits as these plays address the social aspects in a striking way. Both the plays are separated by a span of six decades, and directly or indirectly discuss social evils such as prostitution. The sociocultural contexts depicted in both the plays reflect the changed societal values with an emphasis on women.

\section{Discussion: The plays - Kanyasulkam \& Chavakudadu}

Modern Telugu drama experienced a watershed moment when Gurajada Apparao's seven-act play Kanyasulkam was first staged in 1892. It is an interesting fact that this play was staged prior to its publication in 1897 . It gained immense popularity and attention immediately. However, it is only much later that it was translated into English. The first English translation by S. N. Jayanthi appeared in 1964. Next, in 1976, an abridged translation was published by S. G. Murthy and K. Ramesh. C. Vijayasree and T. Vijay Kumar translated and published the complete text in 2002. The most recent translation was published in 2007 by Velcheru Narayana Rao. The title of this translation is 'Girls for Sale: A play from colonial India'. Chavakudadu (1952) was written by the critically acclaimed playwright and screenwriter Acharya Athreya. His real name is Kilambi Venkata Narasimhacharyulu. $\mathrm{He}$ is one of the playwrights who pushed the boundaries of modern Telugu theatre. This play has all female characters and takes place in a hospital ward. This one-act play is translated as 'Shouldn't die'.

\section{Problematics}

The very first dialogue uttered by Madhura-vani the female protagonist of Kanyasulkam draws reader's attention to the 
social practices prevalent at the time. The dialogue between Madhura-Vani and her paramour reads as follows:

Excerpt 1:

Ramap-pantulu: (Takes a cigar, bites off its end.) Give me a light, honey.

Madhura-vani: (As she strikes a match and lights the cigar, Pantulu pinches her cheek. Madhura-vani drops the match even before the cigar is lit and steps back angrily.) Anyone, man or woman, should have principles. I told you not to touch me, but you wouldn't listen.

Ramap-pantulu: Everything has been finalized. I'm keeping you as my woman, and I'm just waiting for an auspicious day to take you to my village. Why do you still act as if you were under some nincompoop's hold? What's this pretense of chastity?

Madhura-vani: Just because I'm a pleasure-woman, you can't take me lightly. Even we have our morals. I'll call my master Girisam-garu and tell him, "Sir, I'll go my way and you go your way." I'll cut myself loose from him. But until that time, consider me his woman. You might make fun of him because he was born in a Vaidiki ${ }^{1}$ family, he might be Christianized, and maybe he kept that Day-Meal-Woman. Still, for all these days that great man has been my patron. You're a far better lover than he is and you have stolen my heart, but I must have some gratitude for him, right? (Rao 2007: 28)

A brief introduction to the characters in the above excerpt helps in understanding the issues in translating Madhuravani's references to herself. Narayana Rao (2007: 21) noted

${ }^{1}$ A sub-caste in the Brahmin community 
that Ramap-pantulu is a Niyogi ${ }^{2}$ Brahmin who is the karanam (revenue officer) of Rama-chandra-puram. He thinks he cleverly manages village politics. He enjoys good things in life and keeps Madhura-vani as his pleasure-woman. As a Niyogi, he assumes a proud style and demands to be served and respected. Madhura-vani is a pleasure-woman in Vizianagaram $^{3}$, probably in her twenties. For most of the duration of the play, she is kept by Ramap-Pantulu, and she moves to Rama-chandra-puram with him. In the end she moves to Visakhapatnam, the headquarters of the district.

Kanyasulkam, anchored in social, cultural and language specific traditions is a difficult text to translate. In his note, the translator mentions the untranslatability of dialect and social hierarchy as well. This paper focuses on that part of the text which deals with language of social stigma, taboo and abuse used in portrayal of women and the issues of (un)translatability.

In the source text, the language employed by the author (cf. Apparao 1995: 41) as part of Madhura-vani's dialogues is intriguing. First, she calls herself a vesya, which is translated as 'pleasure-woman'. Next, she addresses herself as saane $(d i)^{4}$, which roughly means prostitute ${ }^{5}$ in English. Of course, providing an exact translational equivalent is a next to impossible task, as no two languages map social and cultural realities identically. But it is necessary to find out what is lost

\footnotetext{
${ }^{2}$ A sub-caste in the Brahmin community

${ }^{3}$ A district in Andhra Pradesh

4 '-di' is a feminine gender marker.

${ }^{5}$ The Telugu Akademi dictionary (which is widely considered as a standard Telugu dictionary) does not provide a definition for the word vesya but provides two other equivalents instead - velayAlu, paNyAngana. The dictionary entry of the word vesya is listed only as a synonym of the word saani (root word). The closest equivalent of both these words in English according to the dictionary is 'prostitute'.
} 
in translation. In Telugu, there are nearly four words that refer to the English word 'prostitute': saani, velayAlu, panyAngana, vesya. Out of these, the words vesya and saani are used in the source text. It is quite interesting to note that the translator chose to render these varied expressions into English with a single expression 'pleasure-woman' with less attention to the connotative value of each of the expressions in the source language. In addition to this, the translator chose not to translate certain parts. At places the translator chooses not to translate certain parts of the dialogue, for reasons best known to him, which may eventually result in loss of translation. In the source text, where the above excerpt's original falls, the author used the word saani but the translator omitted it. Perhaps, the translator chose to use a less offensive, euphemistic expression in the place of saani. At the same time, pleasure-woman seems to be a conscious choice intended to protect and portray the dignity of Madhura-Vani's character as intended in the source text. The other equivalent like 'prostitute' may provide referential equivalence but would fail to capture the social and cultural significance of that character.

Madhura-vani is portrayed to be a bold and independent woman who can exercise choice in selecting her partner. She is not a regular prostitute. Only men from the upper strata visit her. In pre-independent India, prostitution prevailed as a profession and it was a common practice for men of higher castes, especially of the Brahmin community, to 'keep' a woman.

The original play is social-reformist by nature, written with the sole purpose of denouncing the evil practices like bride-price and prostitution. It is a paradox that Madhura-vani, though a prostitute, exhibits a streak of nobility, as in her own words '...just because I'm a pleasure-woman...'. The coinage of the compound expression 'pleasure-woman' may signify the aura 
of nobility surrounding Madhura-vani but somewhere, the social stigma associated with the Telugu word vesya is underplayed in the translation.

The Day-Meal-Woman, a young Brahmin widow who runs a Day-Meal-House for Brahmin men only is another character worth studying. She has no family to take care of her following the death of her husband. So, she cooks for Brahmin men to make a living. She has an affair with Girisam, who plays a pivotal role in the whole play. Girisam is the young and handsome English educated cousin of Lubdha Avadhanulu (who lives in the same village). He has a glib tongue, notes Narayana Rao (2007: 20), and can turn any situation to his advantage. In one instance, enraged at the fact that the DayMeal-Woman revealed his secrets, Girisam abuses her with an epithet munda. It is a term used to refer to a Hindu widow. It is also a term of abuse used to express indignation and disgust. Consider the following excerpt:

Excerpt 2:

Ramap-pantulu: (To himself:) He'll beat me up. How did I get into this mess?

Madhura-vani: Why should it be a man? Don't women have mouths?

Girisam: (To himself:) That slut, the Day-Meal-Woman, is slandering me. (Openly:) A woman told you? God made women live by her loud mouth. But then, why would a respectable woman come to your house? (Rao 2007: 30).

The translator chose the word 'slut' for munda. The word 'slut' has a definite derogatory sense and the modern dictionary meaning for 'slut' is 'a woman who has many sexual partners'. It is to be noted that the Telugu word munda refers to a widowed woman in a derogatory sense. The source 
text did not intend to portray the Day-Meal-Woman as the English 'slut' but the translated text may prompt the English readers to see her not as a widowed Hindu woman but as a casual-sex seeker. The portrayal of the practice of treating young Hindu widows with contempt has disappeared from the translated text with the word 'slut'. This is a good example of the use of an equivalent with an exaggerated semantic import.

Narayana Rao (2007: 159) expounds the context of this play in detail and opines that the two things that cannot be avoided when writing about Apparao are colonialism and modernity. The period in which Kanyasulkam was staged can also be comprehended as the beginning of the end of colonialism and the beginning of modernity. The translator here leaves a cue for the reader in the title of this translated version as 'Girls for Sale: A play from colonial India'. It is against this background that the colonial-identity of Indian women needs to be compared with that of the post-colonial and modern-identity. Words like vesya and munda retained their derogatory and offensive sense while the social reality remained unchanged over decades. This can be observed in the play chavakudadu, which is loosely based on J. B. Priestley's 'An Inspector Call'.

The following excerpt provides a context of play and introduces the characters.

Excerpt 3:

Doctor: HORRIBLE CASES. These come just to trouble us. Should we treat them or hang around courts for their life? NUISANCE!

(She stood up. The sister came with a basin and a hand towel. The doctor washed her hands. At that moment, a svelte looking woman came in hurriedly. Maybe because she came from outside, she wore sunglasses, which she removed after coming in. Neatly cut hair, high heels; 
looking sexy in the way she wore the saree. Watch on the wrist, lipstick, there is something like a Bindi ${ }^{6}$ on her face. She looks fair, tall and slender).

Rajini: HELLO doctor!

There are three main female characters in this play. One is the doctor, the other is Rajini, a women's rights activist and the other woman is addressed as Patient - a victim of cheating and deception by the men in her life. The plot revolves around this Patient, who kills her child and attempts suicide. She reveals some astonishing facts about the men in her life towards the end. This play is the story of a woman (Patient) who is deceived by her lover and also by a few other men. She bears a child out of wedlock and is abandoned by everyone including a women's association and so she decides to commit suicide. Eventually, she ends up in a hospital where she incidentally meets the women who cheated her in one or the other way. To better understand the characters, let us read another excerpt from the same play.

Excerpt 4:

Doctor: She looks like a streetwalker.

Rajini: A prostitute?

Doctor: Maybe.

Rajini: If so, why would she commit suicide?

Doctor: Just unable to live. That's all.

Rajini: Did she tell you about herself or her life?

Doctor: They have a life! And a past! Of the worst kind...they are the unwanted in the society. Disgrace to the nation.

Rajini: This time, the Mahila Sangham ${ }^{7}$ working committee is going to discuss the issues of such women

${ }^{6}$ A decorative mark (with vermilion, if Hindu) worn in the middle of the forehead by Indian women. 
seriously. As long as woman has no financial independence, we will see tragic incidents like these.

Here, the 'she' is the Patient that both the Doctor and Rajini talk about. The doctor is a well-educated, hard-working woman and Rajini, an educated and an affluent woman. The author describes her looks, her dress and how attractive she is. Both Rajini and the Doctor refer to the patient as a 'streetwalker' and 'prostitute'- the translational equivalents for bazaaru(di) and vesya - while making wild guesses about her real life. These elite women have no qualms to stoop down to use derogatory language while referring to 'another woman', a poor destitute.

Another excerpt from Chavakudadu reads as follows:

\section{Excerpt 5:}

Patient: (...) my life is of no use, but I'll tell you the truth and die... we are all responsible and take part in everything that happens in this world. Don't try to wash hands off it saying you are no way related... I sold my chastity. I'm a virtuous woman. Men who talk morals would come for me. (...).

As in the case of 'pleasure woman' the English word 'chastity' also holds some significance concerning translation. When Ramap-pantulu says that Madhura-vani is pretending 'chastity' (cf. excerpt 1) the word used in the source text is pAtivratyam, which denotes a sense of respect for monogamy and high regard for a woman's husband. It also connotes a loyal, dutiful and an ideal wife. In the context of 'Girls for sale' 'chastity' is used in an ironic sense while referring to Madhura-vani. 'Chastity 'in the second play is used as an equivalent for the Telugu word sIlam (1982: 451). The word sIlam carries multiple connotations and attributes such as self-

${ }^{7}$ A Mahila Sangham is a women's association. 
respect, virginity, righteousness, and moral conduct. Though sIlam and pAtivratyam are different characters of a woman, the English word 'chastity' comes as the nearest equivalence. The distinction between the two female-characteristics seems to have been blurred.

With reference to the likes of problems of translation in the excerpt 2, the below excerpt from 'Shouldn't die' demonstrates how translation can exaggerate or flatten a character.

Excerpt 6:

Sister: You (tried recollecting) you are Indira right?

Patient: A (... Yes, I am Indira.

Rajini: $O H M Y G O D$ ! So many names.

Doctor: SHE SEEMS TO BE A CHEAT. She actually seems to be a cheat.

Rajini: Also, a SCOUNDREL!

2nd patient: She's a bloody bitch.

Doctor: Yes. So, I see.

Rajini: She's trying to fool us with her drama and play us.

The above excerpt has a considerable amount of similarity with the one from Dr. Narayana Rao's translation. An unnamed patient lying in the ward says that the 'Patient' is a 'bloody bitch' assuming she is a liar. The context aside, the word dongamunda was used in the place of 'bitch' in the source text (Athreya 1982: 450). This word is a compound with an adjective donga. However, it more or less means the same as munda and is used mostly with intended offence. This same usage would have brought forward the intended meaning in Narayana Rao's text too. Comparing these two excerpts, it can be stated that the translation strategy should be centred in the dialogue and the reaction of the other characters more than anything else as it is the only space where the reader can find out how characters perceive each other. 
The conclusions drawn from the above two texts is that in addition to culture and language specific epithets, the choice of equivalents is also driven by the genre of the text to be translated. The question which arises now is why drama is different from other literary practices, or art forms for that matter, and how unique is drama translation. Drama certainly poses uniqueness because it progresses only with dialogues. Though brief descriptions about the characters (dramatis personae) and the setting are found at places, they do not help in framing the true nature, purpose and the life of a particular character. The only way a character takes birth is through its own dialogue. The only way the complete character of a particular character is revealed to the audience is through the dialogues of other characters. So, when those dialogues fall flat in translation, the source text suffers a loss of identity. We name it 'translation loss'. In situations like these, the potential of the characters like Madhura-vani may be thinned down if the translator selectively omits certain parts of the source text which stand as impediments in the process of translation.

While resolving the issue of untranslatability, many compromises have to be made. When the translator tries to attain equivalence, s/he may lose a few shades of a character. Striking a balance between the source text and target text is subject to a number of limitations on the part of the translator and the language and culture involved. So, translation is never complete, or is so only transitionally (Sujit Mukherjee 2004). Ultimately, the purpose of translation needs to be served well. When it comes to drama and theatre, drama is consumed by two different people, readers and audience. Therefore, a translated drama is not always meant to be staged.

\section{Conclusion}

To solve the problems of translation, almost all critics, researchers and translators suggest to consider performability 
and speakability (of the translated dialogue) as strategic factors. It is understood that apart from linguistic competence, the translator should be equipped with additional qualifications for the task and meet the differing criteria of the medium. The function and purpose of the target language text have determined for many the primary criterion by which the product is appraised - speakability (Kevin Windle 2011: 1). As Walter Benjamin states (2000: 19), The Task of The Translator consists in finding that intended effect upon the language into which he is translating which produces in it the echo of the original, the process of this translation emphasises on language, dialogue and characterization. Having said that, when a translator yields a loss in translation, in regard of performability and/or speakability (of the dialogue), it is advisable to have two different translations, one for the reader and one for the stage. The version for the stage may accommodate translation at the cost of better performance and the version for the reader should try to retain the source language culture as much as possible.

The twin argument is that not all dramatic texts are intended for performance. As a matter of fact, the distinction between a play and a dramatic text has clearly been drawn. Bob Dylan, in his Nobel acceptance lecture (2016) mentioned that, "[...] the words in William Shakespeare's plays were meant to be acted on stage". But in reality, we read them today, like the works of many other playwrights. The way we perceive certain literary genres and why we perceive certain literary genres has fundamentally changed in due course of time, in the past 400 years so as to say. Polizzotti's argument that translation is a royal road to cross-cultural understanding seems rational and logical in this context. Adding to his own observation, Bob Dylan said that he would suggest people listen only to his songs and not read his lyrics, for the song and lyrics were written together. Though he was awarded the prize in the 
literature category, he couldn't see his lyrics and music in isolation. Therefore, it is relevant to ask whether the dramatic texts published decades/centuries ago and their respective translations are really inseparable from performance. If it is so, we should watch a play and not read it. Of course, there are theatrical translations of Shakespeare's plays into various Asian languages, for example Vietnamese, which have been staged successfully. However, the vast majority of translated plays is not being performed but is only read.

The translator Velcheru Narayana Rao (2007: 195) said in his introduction to the play that his (the) translation is not suited for performance for its length - and other reasons too - and so if it is not trimmed to a stageable length, it is suitable only for reading. If there is no scope for performance for a translated drama, how different would it stand from the other translated literary genres like novel or short story? Therefore, if the purpose of translation is determined, the purpose of translated literature will be served. Hence, to translate dramatic texts in the lines of speakability and performance is not advisable at all times. New methodologies that lessen the translation loss are to be explored to fill this gap.

\section{References}

Polizzotti, Mark. 2018. Sympathy for the Traitor. Cambridge \& Massachusetts: The MIT Press.

UBERSFELD, ANNE. 1999. Reading Theatre. Toronto: University of Toronto Press.

BASSNetT, SusAn. 2002. Translation Studies. London \& New York: Routledge.

Narayana RaO, Velcheru. 2007. Girls for Sale: A Play from

Colonial India. Indiana: Indiana University press.

APPARAO, GURAJADA. 1995. Kanyasulkam. Jayanthi Publications. 
REDDY, G. N. and SRINIVASACHARYUlu, BOMMAKANTI (eds.). 2007. English-Telugu Dictionary. Hyderabad: Telugu Akademi.

RAO, GAngadHara. (ed.). 1982. Naatika Panchavimshati. Andhra Pradesh Sahitya Akademi. 435-452

MukHERJEE, SuJIT. 2004. Translation as Recovery. Delhi: Pencraft International.

Benjamin, Walter. 2000. The Task of the Translator. In Lawrence Venuti (ed.), The Translation Studies Reader. London \& New York: Routledge. 15-25.

Windle, KEVIn. 2011. The Translation of Drama: The Oxford Handbook of Translation Studies. Oxford University Press.

$$
* * *
$$

Cite this work:

GiRISH, G. SATYA and RAJYARAM, K. 2020. Translating Drama: An Interpretation, an Investigation. Translation Today, Vol. 14(1). 35-49. DOI: 10.46623/tt/2020.14.1.ar3 